\title{
Utilizing Behavioral Economics to Understand Adherence to Physical Activity Guidelines among a Low-Income Urban Community
}

\author{
Kerem Shuval, Xia Si, Binh T. Nguyen, and Tammy Leonard
}

Short title: Behavioral Economics and Physical Activity

Manuscript type: Original Research

Funding: The Fair Park Study was funded by the National Science Foundation (NSF/SES-0827350).

Keywords: physical activity; monetary savings; low income; urban population

Abstract word count: 190

Manuscript word count: 2,826

Tables: 3

Figures: 0 


\begin{abstract}
Background: Behavioral economics studies have found that individuals with more patient time preferences, i.e. greater willingness to forgo current costs for future benefits, are more likely to save money. Although research has observed significant relationships between time preferences and health-promoting behaviors, scant evidence exists with physical activity as an outcome.
\end{abstract}

Methods: We examined the association between monetary saving behaviors and physical activity among adults of low-income who reside in an urban community. Specifically, we assessed the relationship between saving behaviors (checking/saving account, monthly savings, and planning family finances), and future orientation to physical activity as a dichotomous (meeting guidelines) and continuous (total and domain specific) endpoint.

Results: In multivariable regression, being future-oriented and having a checking/saving account were related to a 1.3 and 2.1 times higher (respectively) likelihood of meeting physical activity guidelines $(\mathrm{p}<0.05)$. When examining physical activity continuously, all measures were significantly related to leisure-time activity $(\mathrm{p}<0.05)$.

Conclusions: Our study findings establish a relationship between future time preferences and increased levels of physical activity among low-income adults. Future research should prospectively explore the efficacy of various schemes that help individuals overcome impatient time preferences to determine a causal relationship. 
Ample evidence from epidemiological, experimental and physiological studies supports a causal relationship between sufficient physical activity and the prevention or delay of numerous chronic diseases (e.g. type 2 diabetes) and premature mortality from all causes, cardiovascular disease and cancer. ${ }^{1}$ Specifically, a recent analysis of burden of disease and life expectancy worldwide, has estimated that not meeting physical activity guidelines significantly increases the risk for coronary heart disease by $16 \%$, type 2 diabetes by $20 \%$, breast cancer by $33 \%$, colon cancer by $32 \%$, and all-cause mortality by $28 \%{ }^{2}$ For chronic disease mortality and morbidity prevention current Health and Human Services Guidelines encourage engaging in physical activity of moderate intensity for 150 minutes or of vigorous intensity for 75 minutes weekly (or a combination of both). ${ }^{1}$ Yet despite these recommendations, less than half (48.4\%) of US adults meet these recommendations based on a nationally representative survey. ${ }^{3}$

To increase the population's physical activity levels it is paramount to first understand the underlying factors that impede engaging in health promoting physical activity. ${ }^{4}$ While numerous studies have utilized health behavioral theories and constructs, such as the transtheoretical model and stages of change, to understand and promote physical activity, ${ }^{5}$ scant research has been conducted in the context of behavioral economics and physical activity. Behavioral economics, the application of psychology to economics, seeks to understand the boundaries of rational decision-making, as well as the social, emotional and cognitive factors that influence decisions. ${ }^{6,7}$ When bounded rationality and other social or cognitive factors lead to sub-optimal behavioral choices, behavioral economists have suggested intervention and policy approaches that prompt (or 'nudge') individuals to engage in healthful behaviors to reduce future disease risk. ${ }^{8-10}$ 
Impatient time preferences, in which individuals experience an inherent preference for immediate utility over delayed benefits in the future, often leads to present-bias decisionmaking. ${ }^{11}$ For example, regularly engaging in health-promoting physical activity involves immediate tangible costs, such as loss of time; however, the benefits (e.g. reduced risk for hypertension) are delayed and appear uncertain. ${ }^{12}$ Thus, due to this intangible and often delayed benefit, individuals with less patient time preferences might not engage in physical activity. A lack of patient time preferences has been associated in numerous studies with unhealthy lifestyle behaviors, such as smoking and heavy drinking. ${ }^{13-15}$ Scant empirical evidence exists, however, pertaining to time preferences and physical activity. Our research attempts to bridge this gap in the literature by examining the association between time preferences and physical activity among a sample of adults from the Fair Park Study.

\section{Methods}

\section{Participants and Design}

Our data come from the third wave of data collection of the repeated cross-sectional Fair Park Study, which is elaborately described elsewhere. ${ }^{12,16}$ The primary study aim was to assess the impact of public investment on behaviors and outcomes of Fair Park neighborhood residents. The Fair Park neighborhood is located in Dallas, Texas, and primarily comprises low-income (median household income: \$19,939), ethnic minority individuals (70\% African American and $26 \%$ Hispanic). ${ }^{17}$ Participants in the current analytic sample consisted of 420 adults aged 20 to 75 years (of 504 from the entire wave conducted between April to May 2012) who provided information pertaining to the primary independent and dependent variables. Analytic samples 
varied slightly in the models due to some missing responses (see Tables 2 and 3). The research was approved by the University of Texas at Dallas Institutional Review Board, and all Fair Park study participants provided written informed consent. ${ }^{16}$

\section{Measures}

Physical activity, the dependent variable, was based on participants' responses to the Short Questionnaire to Assess Health-enhancing physical activity (SQUASH). ${ }^{18}$ In the SQUASH, participants were asked to report the frequency, duration and intensity (when germane) of physical activity during a typical week in the past month. Specifically, individuals were queried about their physical activity in four domains: commuting (e.g. cycling to work), leisure time (e.g. walking, sports), household (e.g. washing dishes), and occupation (e.g. heavy lifting at work) activities. Reported frequency and intensity of each activity was multiplied by a metabolic equivalent (MET) value based on the physical activity compendium. ${ }^{19}$ MET minutes of physical activity per week were summed across domains to provide domain-specific MET values. In addition, overall physical activity was computed by summing MET values across domains. For analysis, we examined the continuous MET values for total physical activity, commuting, leisure time activity, and work-related physical activity (a compilation of household and occupational METs). We combined household and occupation METs, since $64.3 \%$ of the sample were unemployed. Moreover, physical activity was dichotomized into meeting current Health and Human Services physical activity guidelines of $\geq 500$ MET minutes per week (yes/no). ${ }^{1}$

In addition, four primary independent variables were used as proxies of time preferences: future orientation; having a checking, savings, and/or investment account (henceforth 'checking/saving'); monthly monetary savings; and planning family finances. The first variable 
is based on a psychological measure of time preference, while the remaining three relate to monetary saving behaviors, which is a commonly used proxy for time preferences..$^{20,21}$ Future orientation was determined based on responses to a survey question asking participants to indicate the degree to which they are future oriented (rarely/never, occasionally, often, and almost always). ${ }^{20}$ In addition, participants were asked to indicate whether they have a checking/saving account, and to specify the dollar amount they save each month. While having a checking/saving account was regarded as a dichotomous (yes/no) variable, monthly savings (\$) was grouped into 4 categories: $\$ 0, \$ 1$ to $<\$ 50, \$ 50$ to $<\$ 100$, and $\geq \$ 100$. Additionally, the time horizon considered when planning family finances was examined as a categorical variable: next few months, next year, next few years, 5 to 10 years, and $\geq 10$ years. $^{21}$

\section{Covariates}

We adjusted for the following covariates in multivariable analyses: age, sex, race/ethnicity, employment status, marital status, income, education, children $<18$ years, self-reported health status, health insurance, and body mass index (BMI). All covariates were based on survey responses except BMI, which was based on objectively measured height and weight using the standard formula $\left(\mathrm{kg} / \mathrm{m}^{2}\right)$.

\section{Statistical Analysis}

Descriptive statistics were utilized to depict participants' characteristics. The association between the primary independent variables related to time preference (i.e. future oriented, checking/saving account, monthly savings, and planning family finances) and the dependent 
variable (meeting physical activity guidelines) was examined using logistic regression in both adjusted and unadjusted models. In addition, Tobit regression models were computed with total physical activity and domain-specific physical activity (leisure, work-related, and transportation) as continuous dependent variables, while controlling for covariates. Separate models were constructed for each primary independent variable in relation to total physical activity and domain-specific physical activity. Analyses were performed using STATA version 13 (College Station, Texas).

\section{Results}

Participant characteristics are depicted in Table 1. On average, participants were 44.1 years old $(\mathrm{SD}=12.3)$, slightly less than half were women (48.8\%), and most (88.3\%) were Non-Hispanic blacks. In addition, $81.7 \%$ were not married, $73.1 \%$ did not have children, and $38.3 \%$ did not have health insurance. With regards to health, on average participants were in the overweight category (mean $\mathrm{BMI}=29.9, \mathrm{SD}=7.8$ ), and $30.9 \%$ reported poor or fair health. In addition, $71 \%$ met Health and Human Services guidelines for physical activity, mostly stemming from leisure time and work-related physical activity (Table 1). Most (93.6\%) reported an annual household income of $\langle \$ 40,000$, and $76.6 \%$ reported having a checking/saving account. On average, participants saved $\$ 62.10(\mathrm{SD}=107.5)$ monthly.

The bivariate and multivariable association between the independent variables and meeting physical activity guidelines is presented in Table 2. In bivariate analysis, future orientation, having a checking/saving account, saving more money on a monthly basis, and planning ahead with regards to family finances, were all significantly associated with meeting physical activity 
guidelines ( $\mathrm{p}<0.05$ for all, Table 2). In each case, the bivariate results supported the association between more patient time preferences and an increased likelihood of meeting physical activity guidelines. When examining these associations while adjusting for covariates in multivariable logistic regression, two independent variables remained statistically significant: being future oriented, and having a checking/saving account (Table 2). Specifically, a one-unit increase towards becoming more future oriented (e.g. from 'occasionally' to 'often' future oriented) was related to a 1.3 times higher likelihood of meeting physical activity guidelines ( $\mathrm{OR}=1.29 ; 95 \%$ $\mathrm{CI}=1.04-1.58)$. Similarly having a checking/saving account (versus not having an account) was associated with a 2.1 times higher likelihood of meeting physical activity guidelines (OR=2.07; $95 \% \mathrm{CI}=1.19-3.57)$.

Table 3 presents multivariable regression estimates for the relationship between monetary savings and future orientation to physical activity measured as a continuous variable. Each of the primary independent variables was significantly related to the continuous measure of leisuretime physical activity (Table 3). For example, when planning family finances, transitioning to a higher category (versus not changing categories) was associated with an average increase of 276.3 MET minutes per week (95\% CI=12.88-539.67) for leisure-time physical activity. None of the relationships between the independent variables and the other domains of physical activity were statistically significant (Table 3). 


\section{Discussion}

The current study aimed to explore the relationship between monetary savings and future orientation (as proxies of time preferences) and engaging in health-promoting physical activity. Our findings indicate that individuals who have more patient time preferences, that is, who are willing to 'pay immediate costs' (e.g. loss of time) in return for future, often uncertain, benefits (e.g. improved long-term health), ${ }^{9}$ are more likely to engage in health-promoting physical activity. Specifically, we observed that those who indicated that they were future oriented were $29 \%$ more likely to meet physical activity guidelines. Individuals with checking/saving accounts were more than twice as likely to meet guidelines, controlling for income and other potential confounders. In addition, having a longer time horizon with regards to planning family finances, as well as saving money on a monthly basis, were significantly associated with higher leisure time physical activity levels, yet not with meeting guidelines. Previous research has found time preferences to be related to a number of modifiable health behaviors (e.g. smoking, diet), yet scant research has examined its association with physical activity. ${ }^{11,13}$ In an earlier study, focusing on a smaller sample, ${ }^{12}$ we found time preferences to be related to the intention to be physically active (via the stages of change model). In contrast, Adams and Nettle (2009), examining data collected from a web-based survey of urban locations in the US, did not find an association between time preferences and physical activity. ${ }^{22}$

Our significant findings with regards to leisure-time physical activity (but not other domains, such as transportation), suggest that time preferences are primarily associated with the explicit choice to engage in physical activity. ${ }^{23}$ The motivation to engage in leisure-time physical activity differs from motivations for work-related and transportation physical activity. ${ }^{24}$ Among this very

low-income population, access to a private motor vehicle is often limited, ${ }^{25}$ hence transportation 
physical activity might often be undertaken not because the individual is choosing physical activity to promote health, but because there is no alternative means of transportation. Likewise, as employment opportunities are limited, occupational physical activity is likely chosen because such jobs are more readily available, rather than the desire to be physically active to achieve the health benefits associated with an active lifestyle. The fact that the relation between time preferences and physical activity is most robust for leisure-time physical activity, which is also the domain in which decisions are based most fully on an explicit intent to be physically active, is in line with the extant literature of theories for investment in health promoting activities. ${ }^{26-29}$

While our analysis was only able to assess the cross-sectional relations between time preferences and physical activity, a causal relationship has theoretical support. ${ }^{26-29}$ In fact, Zimmerman (2009) has called for the use of behavioral economics to promote physical activity, ${ }^{30}$ yet few empirical studies have been conducted. Specifically, impatient time preferences may be viewed as producing decision errors whereby individuals forgo costly activities that are in their longterm best interests (e.g. physical activity). Hence, physical activity might be viewed, particularly among those with impatient time preferences, as costly not only in terms of actual monetary costs (e.g. required for fitness club membership), but also costly in terms of the time and energy required to exercise, which might lead to inactivity despite future health benefits. The growing body of behavioral economics literature aims to exploit these inherent decision errors to improve health behaviors and subsequently lower the risk for adverse health outcomes. Leowenstein et al. (2007) suggest enabling health behaviors to be less costly (i.e. more convenient), and for incentives (or rewards) to be immediate to facilitate health behavior change. ${ }^{8,9}$ For example, Volpp (2008) found a weight loss intervention guided by behavioral economics (including immediate financial 'consequences' and participant feedback) to be efficacious in short-term 
weight loss. ${ }^{31}$ For the case of physical activity, providing regular physical activity breaks during the work day coupled with immediate and tangible incentives from the employer and/or insurer might be a feasible avenue to improve health and productivity, particularly for individuals with less patient time preferences. ${ }^{9,12}$

Further, clinicians and public health professionals may seek to design innovative interventions that allow for tailoring based on individual time preferences. In the public health realm, it is acceptable practice to place individuals on a continuum from precontemplation to maintenance of health behaviors (i.e. stages of change) to tailor appropriate interventions, such as to provide knowledge of the health benefits of physical activity for precontemplators. ${ }^{32}$ It is likewise feasible to 'screen' individuals for time preferences. ${ }^{12}$ Thus intervention tailoring could then proceed through use of tools such as pre-commitment contracts, supplementing current health approaches for behavior modification. ${ }^{33}$ Pre-commintment contracts, voluntary self-imposed constraints on future choices, have been applied to weight loss interventions to increase their likelihood of success. ${ }^{33,34}$ For example, a sum of money is deposited prior to the initiation of a weight loss program and is lost if not achieving a-priori goals, with the underlying aim of making individuals more cognizant of future risks at present time. ${ }^{33,35}$ This approach has been found to be efficacious in some clinical trials of weight loss, however their effectiveness warrants further examination. ${ }^{31,33}$ Furthermore the feasibility and effectiveness of precommitment contracts should be tailored and examined further in low-income urban communities. Additionally, decreasing the costs (both monetary and time-related) associated with physical activity in urban communities by providing safe and accessible exercise facilities and parks conducive to exercise is paramount alongside increasing present-day awareness to the risks associated with physical inactivity. ${ }^{36}$ 
In addition, one hurdle in advancing the understanding of the relationship between time preferences and physical activity is definition of an easily applied measure of time preferences. The gold standard for measuring time preferences is economic experiments. ${ }^{12,37}$ However, this method is often prohibitively costly to implement in many study settings. In the current study, we analyzed a variety of survey measures that have been used by other researchers as proxies for time preferences, since these types of measures are more feasible for researchers to consider adding to existing data collection protocols. ${ }^{38,39}$ These measures, based on self-report of psychological tendencies and self-report of financial behaviors, provide consistent estimates of a statistically significant relationship with physical activity, despite not using the gold standard of economic experiments.

Study results should be interpreted while taking into account several limitations. First, the study design is cross-sectional, therefore cause-effect between time preferences and physical activity cannot be established; this should be examined utilizing prospective designs to determine a temporal relationship. Second, though the study sample is larger than our previous study, ${ }^{12}$ it is relatively small and focuses on a very low-income ethnic minority population within a specific geographic location. Although caution should be taken when generalizing findings, results are likely to be applicable to other communities with similar socio-economic traits. Finally, physical activity was measured using a self-report survey measure which may be subject to recall bias, resulting in over- or under-reporting. ${ }^{18,40}$ The high prevalence $(71 \%)$ of participants meeting physical activity guidelines in this sample is consistent with findings in the previous wave of this study $(69 \%),{ }^{17}$ yet higher than in the state of Texas overall $(63.7 \%) .{ }^{41}$ Future research on this topic should measure physical activity using both self-report survey instruments and activity 
monitors (e.g. accelerometers) to provide a more comprehensive assessment of physical activity. ${ }^{42}$

Nonetheless, these study findings are novel and establish a relation between participants' time preferences and physical activity. Specifically, we find more patient time preferences to be related to an increased likelihood of engaging in leisure-time physical activity among a lowincome underserved population of adults. These findings are of particular importance due to the higher propensity of this population to experience chronic diseases, yet the potential inability to treat disease onset due to limited resources. Hence promoting a physically active lifestyle among this population is of paramount importance. Utilizing insights from behavioral economics, with a specific focus on time preferences, may have the potential to modify physical activity patterns and subsequently impact morbidity and mortality outcomes. ${ }^{11,31,33}$ Future research should incorporate time preference measures into longitudinal studies and prospectively explore the efficacy of various schemes (e.g. timing of incentives, pre-commitment contracts) on physical activity promotion to determine a cause-effect relationship.

\section{Acknowledgements}

We are grateful to the Fair Park residents who participated in the study. Additionally, we thank John Daniel, MA of the American Cancer Society for editorial assistance.

\section{Funding}

The Fair Park Study was funded by the National Science Foundation (NSF/SES-0827350). The authors do not have any conflicts of interest to declare. 


\section{References}

1. U.S. Department of Health and Human Services. Physical Activity Guidelines for Americans.; 2008. Available at: http://www.health.gov/paguidelines/pdf/paguide.pdf.

2. Lee I-M, Shiroma EJ, Lobelo F, Puska P, Blair SN, Katzmarzyk PT. Effect of physical inactivity on major non-communicable diseases worldwide: an analysis of burden of disease and life expectancy. Lancet. 2012;380(9838):219-29.

3. Centers for Disease Control and Prevention. Exercise or Physical Activity. Available at: http://www.cdc.gov/nchs/fastats/exercise.htm. Accessed January 4, 2014.

4. Bauman AE, Reis RS, Sallis JF, Wells JC, Loos RJF, Martin BW. Correlates of physical activity: why are some people physically active and others not? Lancet. 2012;380(9838):258-71.

5. Garber CE, Allsworth JE, Marcus BH, Hesser J, Lapane KL. Correlates of the stages of change for physical activity in a population survey. Am J Public Health. 2008;98(5):897904.

6. Kahneman D. A Psychological Perspective on Economics. Am Econ Rev. 2003;93(2):162168.

7. Camerer CF, Loewenstein G, Rabin M, eds. Advances in behavioral economics. 1 st ed. Princeton, NJ: Princeton University Press; 2004:3-51.

8. Loewenstein G, Asch DA, Friedman JY, Melichar LA, Volpp KG. Can behavioural economics make us healthier? BMJ. 2012;3482(May):1-3. doi:10.1136/bmj.e3482.

9. Loewenstein G, Brennan T, Volpp KG. Asymmetric paternalism to improve health behaviors. JAMA. 2007;298(20):2415-7.

10. Thaler, Richard H. CRS. Libertarian paternalism. Am Econ Rev. 2003;93(2):175-179.

11. Frederick S, Loewenstein G, Donoghue O. Time Discounting and Preference : A Critical Time Review. J Econ Lit. 2002;40(2):351-401.

12. Leonard T, Shuval K, de Oliveira A, Skinner CS, Eckel C, Murdoch JC. Health behavior and behavioral economics: economic preferences and physical activity stages of change in a low-income African-American community. Am J Health Promot. 2013;27(4):211-21.

13. Fuchs VR. Economic Aspects of Health. National Bureau of Economic Research Conference Report; 1982:93-120. 
14. Cutler DM, Glaeser E. What Explains Differences in Smoking, Drinking, and Other Health-Related Behaviors? Am Econ J Econ Policy. 2005;95(2):238-242.

15. Anderson LR, Mellor JM. Predicting health behaviors with an experimental measure of risk preference. J Health Econ. 2008;27(5):1260-74.

16. Leonard TCM, Caughy MO, Mays JK, Murdoch JC. Systematic neighborhood observations at high spatial resolution: methodology and assessment of potential benefits. PLoS One. 2011;6(6):e20225.

17. Shuval, Kerem, Leonard T, Murdoch J, Caughy MO, Kohl HW, Skinner CS. Sedentary Behaviors and Obesity in a Low Income, Ethnic Minority Population. J Phys Act Heal. 2013;10(1):132-136.

18. Wendel-Vos GW, Schuit AJ, Saris WH, Kromhout D. Reproducibility and relative validity of the short questionnaire to assess health-enhancing physical activity. J Clin Epidemiol. 2003;56(12):1163-1169.

19. Ainsworth BE, Haskell WL, Herrmann SD, et al. 2011 Compendium of Physical Activities: a second update of codes and MET values. Med Sci Sports Exerc. 2011;43(8):1575-81.

20. Matthew S Stanford ESB. Factor structure of the Barratt impulsiveness scale. J Clin Psychol. 1995;51(6):768-774.

21. The Survey of Consumer Finances. Board Governors Fed Reserv. Available at: http://www.federalreserve.gov/econresdata/scf/scfindex.htm. Accessed January 23, 2014.

22. Adams J, Nettle D. Time perspective, personality and smoking, body mass, and physical activity: an empirical study. Br J Health Psychol. 2009;14(Pt 1):83-105.

23. Keller PA, Harlam B, Loewenstein G, Volpp KG. Enhanced active choice: A new method to motivate behavior change. J Consum Psychol. 2011;21(4):376-383.

24. Beenackers M a, Kamphuis CBM, Giskes K, et al. Socioeconomic inequalities in occupational, leisure-time, and transport related physical activity among European adults: a systematic review. Int J Behav Nutr Phys Act. 2012;9:116.

25. Raphael S, Berube A, Deakin E. Socioeconomic Differences in Household Automobile Ownership Rates: Implications for Evacuation Policy.; 2006. Available at: http://escholarship.org/uc/item/7bp4n2f6.

26. Grossman M. On the concept of health capital and the demand for health. J Polit Econ. 1972;80(2):223-255.

27. Grossman M. The human capital model. Handb Heal Econ. 2000;1:347-408. 
28. Chiteji N. Time-preference, Non-cognitive Skills and Well-being across the Life Course: Do Non-cognitive Skills Encourage Healthy Behavior? Am Econ Rev. 2010;100(2):200204. doi:10.1257/aer.100.2.200.Time-preference.

29. Huston SJ, Finke MS. Diet Choice and the Role of Time Preference. J Consum Aff. 2003;37(1):143-160.

30. Zimmerman FJ. Using behavioral economics to promote physical activity. Prev Med (Baltim). 2009;49(4):289-91.

31. Volpp KG, John LK, Troxel AB, Norton L, Fassbender J, Leowenstein G. Financial Incentive - Based Approaches for Weight Loss. JAMA. 2008;300(22):2631-2637.

32. U.S. Department of Health and Human Services NI of H. Theory at a Glance: A guide for Health Promotion Practice. Natl Cancer Inst. 2005:9-15. Available at:

http://www.cancer.gov/cancertopics/cancerlibrary/theory.pdf. Accessed January 24, 2014.

33. Halpern S, Asch D, Volpp K. Commitment contracts as a way to health. BMJ. 2012;522:e522.doi: 10.1136/bmj.e522.

34. Ariely D, Wertenbroch K. Procrastination, deadlines, and performance: self-control by precommitment. Psychol Sci. 2002;13(3):219-24.

35. John LK, Loewenstein G, Troxel AB, Norton L, Fassbender JE, Volpp KG. Financial incentives for extended weight loss: a randomized, controlled trial. J Gen Intern Med. 2011;26(6):621-6.

36. Shuval K, Hébert ET, Siddiqi Z, et al. Impediments and facilitators to physical activity and perceptions of sedentary behavior among urban community residents: the Fair Park Study. Prev Chronic Dis. 2013;10(1):E177.

37. Kagel JH RA. Handbook of Experimental Economics. Princeton, NJ: Princton University Press; 1995. doi:10.1016/S1574-0722(07)00035-2.

38. Komlos J, Smith PK, Bogin B. Obesity and the Rate of Time Preference : Is there a Connection? J Biosoc Sci. 2003;36(2):209-219.

39. Smith PK, Bogin B, Bishai D. Are time preference and body mass index associated? Evidence from the National Longitudinal Survey of Youth. Econ Hum Biol. 2005;3(2):259-70.

40. Strath SJ, Kaminsky L a, Ainsworth BE, et al. Guide to the assessment of physical activity: Clinical and research applications: a scientific statement from the American Heart Association. Circulation. 2013;128(20):2259-79. 
41. U.S. Department of Health and, Human Services C for DC and P. State Indicator Report on Physical Activity, 2010. Atlanta, GA; 2010:1-13. Available at: http://www.cdc.gov/physicalactivity/downloads/PA_State_Indicator_Report_2010.pdf.

42. Haskell WL. Physical Activity by Self-Report: A Brief History and Future Issues. J Phys Act Heal. 2012;9(Suppl 1):5-10. 
Table 1: Characteristics of Fair Park Study Participants $(\mathrm{N}=420)^{\mathrm{a}}$

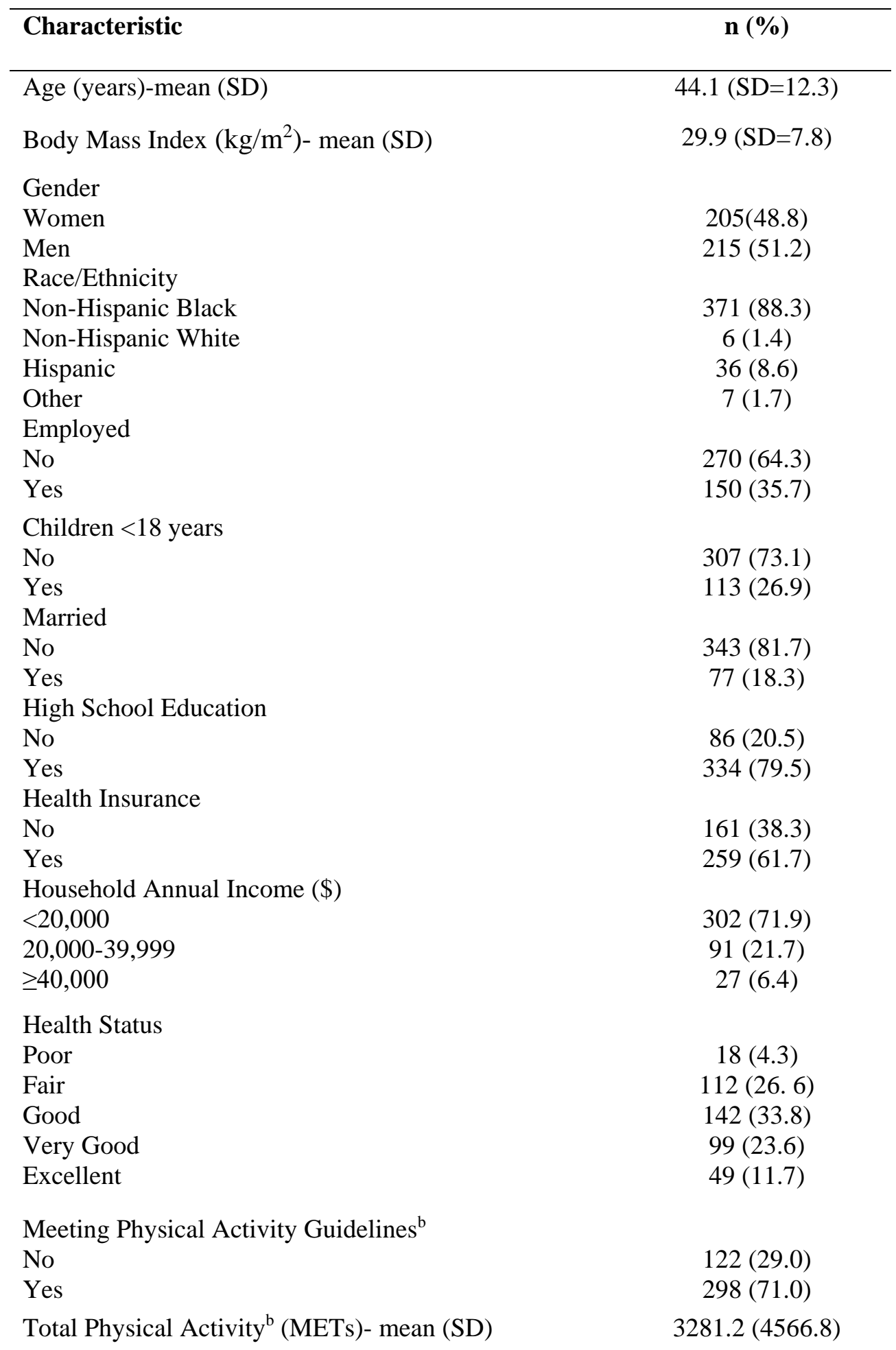


Leisure Time Physical Activity ${ }^{\mathrm{b}}$ (METs)- mean (SD)

1469.9 (2603.6)

Work-related Physical Activity ${ }^{\mathrm{b}}$ (METs)- mean (SD)

$1603.8(2677.2)$

Transportation Physical Activity ${ }^{\mathrm{b}}$ (METs)- mean (SD)

207.5 (924.9)

Future Oriented $^{c}$

Never/rarely

$70(16.7)$

Occasionally

$137(32.6)$

Often

87 (20.7)

Almost Always

$126(30.0)$

Checking/Saving account ${ }^{\mathrm{c}}$

No

$97(23.4)$

Yes

318 (76.6)

Monthly Savings (\$)

0.0

$200(48.8)$

$1.0-49.9$

$59(14.4)$

50.0-99.9

$46(11.2)$

$\geq 100$

105 (25.6)

Planning Family Finances ${ }^{\mathrm{c}}$

Next Few months

231(56.6)

Next year

$59(14.5)$

Next few years

$52(12.8)$

Next 5 to 10 years

$34(8.3)$

$\geq 10$ years

$32(7.8)$

${ }^{\text {a }}$ Some categories do no total 420 due to missing data; percentages are rounded

${ }^{\mathrm{b}}$ Metabolic equivalent (MET) minutes per week were derived from responses to a survey, assessing the frequency, duration and intensity of physical activity. Total physical activity and domain specific physical activity (leisure, work-related, and transportation) were determined from the survey. Meeting physical activity guidelines (no/yes) was based on the 2008 Health and Human Service Guidelines for health promoting physical activity (i.e. $\geq 500$ MET minutes per week).

${ }^{\mathrm{c}}$ Future orientation was determined based on a survey question gauging the degree to which individuals are future oriented (rarely/never, occasionally, often, and almost always). Participants were also asked to indicate whether they have a checking/saving account and to specify the dollar amount they save each month. While having a checking/saving account was regarded as dichotomous (no/yes), monthly savings (\$) was grouped into 4 categories: $\$ 0, \$ 1$ to $<\$ 49.9, \$ 50$ to $<\$ 99.9$, and $\geq \$ 100$. The time period considered when planning family finances consisted of: next few months, next year, next few years, 5 to 10 years, and $\geq 10$ years. 
Table 2: Future Orientation, Monetary Savings, and Meeting Physical Activity Guidelines, Fair Park (Dallas, Texas)

\begin{tabular}{|c|c|c|c|c|c|c|}
\hline & \multicolumn{3}{|c|}{$\begin{array}{l}\text { UNADJUSTED }^{\mathrm{a}} \\
\text { Meeting Physical Activity Guidelines }\end{array}$} & \multicolumn{3}{|c|}{$\begin{array}{c}\text { ADJUSTED }^{\mathrm{a}} \\
\text { Meeting Physical Activity Guidelines }^{\mathrm{b}}\end{array}$} \\
\hline & Odds Ratio & $\begin{array}{l}95 \% \text { confidence } \\
\text { Interval }\end{array}$ & $\begin{array}{l}P \text { - } \\
\text { value }\end{array}$ & $\begin{array}{l}\text { Odds } \\
\text { Ratio }\end{array}$ & $\begin{array}{l}95 \% \text { Confidence } \\
\text { Interval }\end{array}$ & $\begin{array}{l}\text { P- } \\
\text { value }\end{array}$ \\
\hline \multicolumn{7}{|l|}{$\begin{array}{l}\text { Independent } \\
\text { Variable }\end{array}$} \\
\hline Future Oriented $^{c}$ & 1.38 & $1.13,1.69$ & 0.002 & 1.29 & $1.04,1.58$ & 0.019 \\
\hline $\begin{array}{l}\text { Checking/Saving } \\
\text { account }^{\mathrm{c}}\end{array}$ & 1.78 & $1.10,2.88$ & 0.018 & 2.07 & $1.19,3.57$ & 0.009 \\
\hline $\begin{array}{l}\text { Monthly Savings } \\
(\$)^{c}\end{array}$ & 1.20 & $1.00,1.43$ & 0.044 & 1.16 & $0.96,1.41$ & 0.130 \\
\hline $\begin{array}{l}\text { Planning Family } \\
\text { Finances }^{c}\end{array}$ & 1.20 & $1.00,1.42$ & 0.045 & 1.17 & $0.97,1.41$ & 0.093 \\
\hline
\end{tabular}

${ }^{a}$ Unadjusted analysis was conducted by entering each primary independent variable separately into a logistic regression model with meeting physical activity guidelines as the dependent variable. In comparison, multivariable logistic regression was utilized with separate models for each independent variable in relation to meeting physical activity guidelines, while adjusting for: age, sex, race/ethnicity, employment status, marital status, income, education, children $<18$ years, health status, health insurance, and body mass index. The sample sizes varied in models due to missing responses: future oriented: $n=420$; checking/saving accounts: $n=416$; monthly savings: $\mathrm{n}=411$; and planning family finances: $\mathrm{n}=409$.

${ }^{\mathrm{b}}$ Meeting physical activity guidelines (no/yes) was based on the 2008 Health and Human Service Guidelines for health promoting physical activity (i.e. $\geq 500$ MET minutes per week).

${ }^{c}$ Future orientation was determined based on a survey question gauging the degree to which individuals are future oriented (rarely/never, occasionally, often, and almost always). Participants were also asked to indicate whether they have a checking/saving account and to specify the dollar amount they save each month. While having a checking/saving account was regarded as dichotomous (no/yes), monthly savings (\$) was grouped into 4 categories: $\$ 0, \$ 1$ to $<\$ 49.9, \$ 50$ to $<\$ 99.9$, and $\geq \$ 100$. The time period considered when planning family finances consisted of: next few months, next year, next few years, 5 to 10 years, and $\geq 10$ years. 
Table 3: Future Orientation, Monetary Savings, and total and domain specific Physical Activity, Fair Park (Dallas, Texas): Adjusted Models ${ }^{\mathrm{a}}$

\begin{tabular}{|c|c|c|c|c|c|c|c|c|c|c|c|c|}
\hline & \multicolumn{3}{|c|}{ Total Physical Activity ${ }^{b}$} & \multicolumn{3}{|c|}{ Leisure Time Physical Activity } & \multicolumn{3}{|c|}{$\begin{array}{l}\text { Work-Related Physical } \\
\text { Activity }\end{array}$} & \multicolumn{3}{|c|}{$\begin{array}{l}\text { Transportation Physical } \\
\text { Activity }\end{array}$} \\
\hline & METs & $95 \% \mathrm{CI}$ & $\begin{array}{l}\text { P- } \\
\text { value }\end{array}$ & METs & $95 \% \mathrm{CI}$ & $\begin{array}{l}\text { P- } \\
\text { value }\end{array}$ & METs & $95 \% \mathrm{CI}$ & $\begin{array}{l}\text { P- } \\
\text { value }\end{array}$ & METs & $95 \% \mathrm{CI}$ & $\begin{array}{l}\text { P- } \\
\text { value }\end{array}$ \\
\hline $\begin{array}{l}\text { Independent } \\
\text { Variable }\end{array}$ & & & & & & & & & & & & \\
\hline Future Oriented $^{\mathrm{c}}$ & 828.37 & $396.03,1260.72$ & 0.000 & 849.67 & $537.16,1162.18$ & 0.000 & 255.41 & $\begin{array}{l}-15.75 \\
526.56\end{array}$ & 0.065 & -103.06 & $-401.18,195.06$ & 0.497 \\
\hline $\begin{array}{l}\text { Checking/Saving } \\
\text { account }^{\mathrm{c}}\end{array}$ & 1073.14 & $-100.77,2247.06$ & 0.073 & 993.23 & $134.08,1852.37$ & 0.024 & 420.41 & $\begin{array}{l}-311.46 \\
1152.28\end{array}$ & 0.259 & -175.98 & $-968.41,616.46$ & 0.663 \\
\hline $\begin{array}{l}\text { Monthly Savings } \\
(\$)^{c}\end{array}$ & 334.67 & $-65.26,734.61$ & 0.101 & 347.16 & $55.63,638.68$ & 0.020 & 132.07 & $\begin{array}{l}-115.50 \\
379.63\end{array}$ & 0.295 & 6.81 & $-267.87,281.50$ & 0.96 \\
\hline $\begin{array}{l}\text { Planning Family } \\
\text { Finances }^{c}\end{array}$ & 318.21 & $-46.43,682.85$ & 0.087 & 276.28 & $12.88,539.67$ & 0.040 & 68.31 & $\begin{array}{l}-157.53 \\
294.15\end{array}$ & 0.552 & 97.10 & $-145.74,339.95$ & 0.432 \\
\hline
\end{tabular}




\section{MET- Metabolic Equivalents; CI- Confidence Intervals}

${ }^{a}$ Multivariable Tobit regression was utilized with separate models for each independent variable in relation to total physical activity and domain specific physical activity (leisure, work-related, and transportation) as continuous variables, while adjusting for: age, sex, race/ethnicity, employment status, marital status, income, education, children $<18$ years, health status, health insurance, and body mass index. The sample sizes varied in models due to missing responses: future oriented: $n=420$; checking/saving accounts: $n=416$; monthly savings: $n=411$; and planning family finances: $n=409$.

${ }^{\text {b }}$ Physical Activity: Metabolic equivalent (MET) minutes per week were derived from participants' responses to a survey, assessing the frequency, duration and intensity of physical activity. Total physical activity and domain specific physical activity (leisure, work-related, and transportation) were determined from the survey as well.

${ }^{\mathrm{c}}$ Future orientation was determined based on a survey question gauging the degree to which individuals are future oriented (rarely/never, occasionally, often, and almost always). Participants were also asked to indicate whether they have a checking/saving account and to specify the dollar amount they save each month. While having a checking/saving account was regarded as dichotomous (no/yes), monthly savings (\$) was grouped into 4 categories: $\$ 0, \$ 1$ to $<\$ 49.9, \$ 50$ to $<\$ 99.9$, and $\geq \$ 100$. The time period considered when planning family finances consisted of: next few months, next year, next few years, 5 to 10 years, and $\geq 10$ years. 